\title{
An Idiopathic Dalliance in Television, Para-social Relationships, and Consumption: A Study of Pop-Culture Television Nutrition and the Bandwagon Effect
}

\author{
Leah Sycoff ${ }^{1}$ and Charese Cunningham ${ }^{1}$ \\ ${ }^{1}$ Half Hollow Hills High School East, Dix Hills, NY, USA
}

\begin{abstract}
$\underline{\text { ABSTRACT }}$
Although it has previously been established that television causes unhealthy eating habits, uncertainty remains as to how this occurs. This study researches the parameters of viewers forming an emotional investment with the characters in pop-culture television and subsequently becoming influenced by the negative nutritional habits that are promoted. This influence is a form of cognitive bias called bandwagon effect. In context, it can be described as a psychological phenomenon in which the viewer starts to eat unhealthy foods as a result of having formed a para-social bond with television characters and, regardless of previous knowledge and practices, the viewer begins to copy the television characters' food intake regiment. In order to prove this argument, a correlational study was run. Participants, female adolescents and early adults (the most prominent demographic of the show), completed the required consent form preceding survey part one, then watched several episodes of the pop-culture television series Gilmore Girls, known for the aesthetically pleasing protagonists' plentiful consumption of unhealthy food. The participants of the study had unhealthy and healthy food options displayed within grasp while viewing and at completion of the viewing filled out survey part two which asked about food choices. A week later, participants received survey part three to fill out and return to the researcher. Upon receiving the results, data analysis was performed, and the outcome was deemed statistically insignificant even though the hypothesis proved correct. It was found that participants had worse nutrition after watching the pop-culture television series.
\end{abstract}

\section{Introduction}

There exists an omnipresent influencer in the realm of nutrition of which many are unaware. Dietary practices subtly change as viewers eat-up subliminal messages in their daily intake of pop-culture television. Studies continue to target media's influence on teenage girls and their dietary choices, yet these same studies fail to consider cognitive bias resulting from the ideological messages media imposes. Government nutrition initiatives such as MyPlate and its predecessor, MyPyramid, expand and propagandize confusing messages about healthy eating practices, yet few notice the change that pop-culture television imposes upon already confused nutritional patterns (Kealey, 2018; What The Health, 2017). Traditionally, females lead nutritional habits of their household; this phenomenon remains dominant albeit incongruous with today's gender equality expectations. In accordance, publicists and advertising professionals, aware of the power of subliminal marketing, currently utilize neuro-cognitive stimulus as a marketing tool (Pitre, 2019; Batchelor, 2020b). Whereas writers and program professionals deploy tactics to elicit emotional involvement in hope of retaining psychologically invested viewers, they might, too, be unaware of the ramifications of their dietary messages (Diodoro, 2015; Harris \& Bargh, 2009). The innocent viewer and her parents/guardians rarely contemplate these subliminal product suggestions that are inadvertently rooted in pop-culture television programs, yet these emotionally invested viewers remain vulnerable to persuasion as they fall victim to bandwagon effect. 
Each generation remains impacted by various pop-culture television shows that model household eating practices and customs in nutrition.

Historically, pop-culture television establishes women as the head-of-the household responsible for nutritional planning and implementation. Two decades after the invention of television, when it became available to the public “[i]n the 1950's, popular media promoted housewife stereotypes" (Avila, 2020, para. 1). Avila, University of Texas history professor, cites the importance of television in perpetuating a dichotomy between gender roles inside and outside the home. Over decades, leading television shows such as I Love Lucy have appealed to female audiences occupied by household chores by incorporating levity and food intake (Smuskewicz, 2020). Avila explicates, "the stereotypical ideas about housewives [influencing] the way people defined what was 'normal' for real housewives... [goes] beyond the entertainment value that television shows offered, [and presenting] lessons in what was expected from women in society" (Avila, 2020, para. 7). I Love Lucy set this ideological precedent for shows such as Leave It to Beaver in the early sixties, The Brady Bunch and All in the Family throughout the seventies, Roseanne and The Jeffersons in the eighties, and Gilmore Girls at the turn of the century (Maghbouleh, 2020). These television shows, and many others, epitomize "an inherently visual and intensely popular medium in the United States-[conveying] an enormous amount of information about our social world to viewers on multiple, interconnected levels" according to Maghbouleh, professor of sociology (Para. 1). The emotional investment with which we fall into a virtual friendship with the female characters on these lighthearted shows led me to analyze programs that inadvertently define the roles of females as nutritional decision makers.

One pop-culture television show aimed at predominantly female adolescent audiences, Gilmore Girls, exemplifies this inadvertent persuasion when prolifically incarnating cultural eating norms for levity. The aesthetically healthy mother and daughter protagonists gnaw junk food and drink coffee all day long without consequence. Through its established framework and pervasive cognitive parameters, Gilmore Girls, airing for just shy of a decade yet maintaining an enduring presence for two subsequent generations of adolescents, prompts the valid inquiry: To what extent could a pop-culture television series alter nutritional habits of female adolescent viewers and promote trends in nutritional food intake habits through bandwagon effect?

I recently questioned the impetus for my four-cup daily coffee habit. By exploring outside influencers in the quest to understand the exponential growth of my vice, I shockingly discovered that the television show, Gilmore Girls, to which I journey as a method of mindfulness, and have therefore watched three times from start to finish, was potentially the hidden catalyst prompting my caffeine dependence. When I rewatched the first season charting the protagonists' coffee craze, I also forecasted and discovered a possible correlation to food; my sweet habit had also spiked as I became more emotionally involved. I discovered that this dalliance had fostered an idiopathic desire to eat sweets and drink coffee. Concurrently, I failed to contemplate the reality of potential medical repercussions imperceptible in the characters who remain slender and have a continual healthy glow regardless of their diets. I queried if I were the only one influenced by the bandwagon effect? To what extent were others influenced by the quasi-hypnotic connection of the psychology of cinema? Could this phenomenon alter nutritional practices? I decided to enact a microcosmic study through Gilmore Girls, a comedic show promoting scholarly devotion that I could not have imagined would purposefully subvert my habits. I chose this show because it continues to draw a substantial following and might have cajoled several generations of fans.

\section{Literature Review}

Amassing a virtual conversation of scholars enacting studies on various vital facets of media psychology and nutritional marketing underscores concepts and perspectives necessary to prove my hypothesis. 


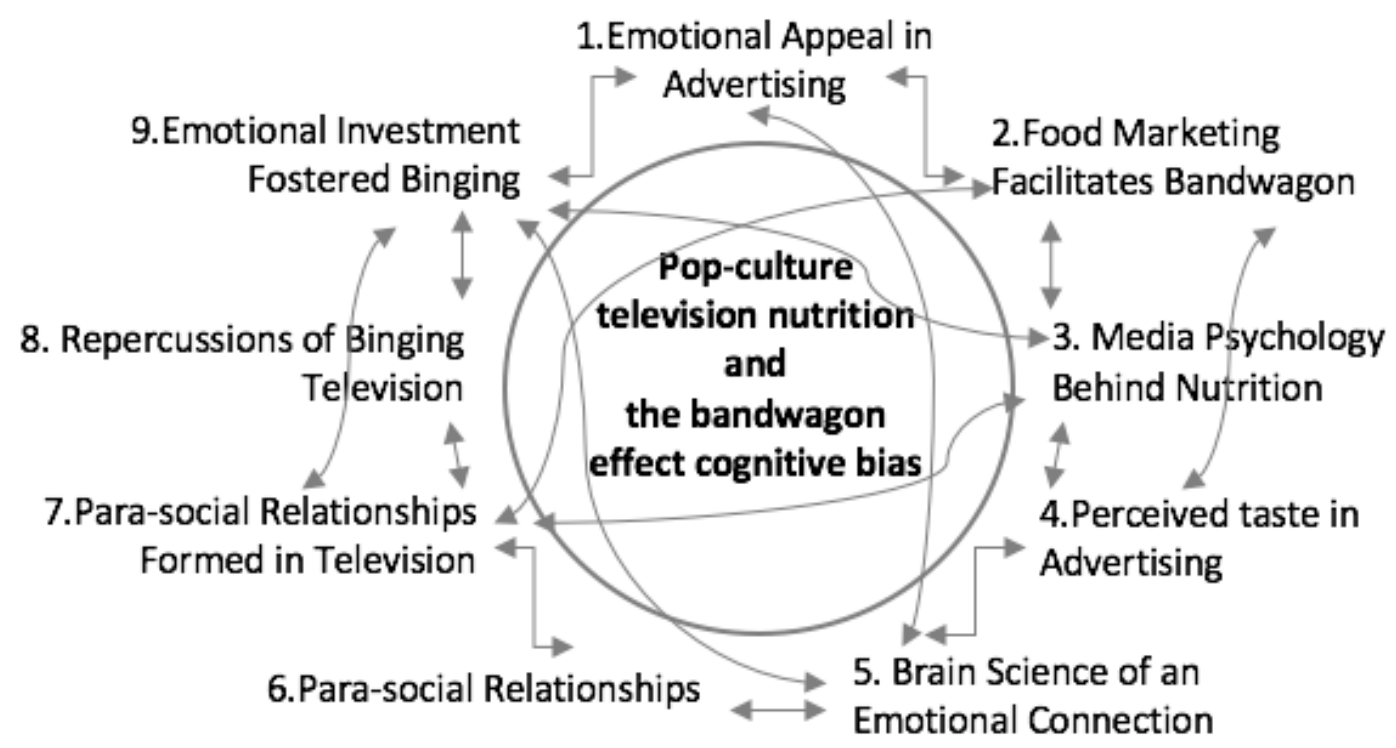

\section{Emotional Appeal in Advertising}

Starting as early as the 1950s, publicists appealed to the emotions of audiences by transforming commercials into miniature stories. Batchelor (2020a), cultural historian and biographer, asserts that they deployed yet-to-be named cognitive bias through celebrities such as Frank Sinatra whose popularity would entice women to buy certain products. This practice "exploited the name recognition of major show business personalities" to promptly enhance connectivity with the audience and manipulate "how the product would make a person feel" (Batchelor, 2020a, para. 8, para. 3). Batchelor (2020b) continues his studies scrutinizing methodologies of media professionals who continue to utilize "the most enticing combination of popular culture and celebrity fascination," such as George Clooney lending "his voice to promote Budweiser" or Jennifer Aniston advertising Smartwater (para. 7, para.8; Shemarya, 2020). These mini-narration advertisements exemplify the principle of a viewer's perceived relationship which facilitates emulation of celebrities.

\section{Food Marketing Facilitating Bandwagon Effect}

Female adolescents follow suggestions regarding nutrition in the media. Accordingly, Jennifer Harris (2009), youth directed food marketing expert, along with John Bargh (2009), both social psychology Yale University scholars, critically associate the convention of media and unhealthy eating. Their "findings provide insights into the potential effectiveness of alternative media interventions to counteract the unhealthy influence of television on diet" (Harris and Bargh, 2009, para. 1). They cite different stages of development and the influence each has, warning that "[a]s children move through middle childhood and adolescence, non-familial influences on eating behaviors increase" and these "outside influences have not been studied extensively" (Harris and Bargh, 2009, para. 6). While Harris and Bargh's interventions lean toward augmenting education and minimizing influence, Batchelor (2020a; 2020b) studies the motives behind media's influence upon the viewer. My study builds upon this body of knowledge correlating the results of their studies with the cognitive bias of bandwagon effect. Bandwagon effect is defined as "a psycho- 
logical phenomenon in which people do something primarily because other people are doing it, regardless of their own beliefs, which they may ignore or override" (Chappelow, 2020, para. 1).

If pop-culture television shows are proven to be an influencer, they could be a mode of helping to reverse the adverse food culture which has been developing since the advent of pop-culture television. In recent years attention has been called via multimedia to the contraindicated food culture by professionals such as Jamie Oliver (2010) and American food journalist Mark Bittman (2007) who alert to mass proliferation through publicizing unhealthy eating practices as healthy. I hypothesize that when adolescent females become emotionally linked to the characters in pop-culture television stories, they develop a false sense of trust which enables a bandwagon action of copying the actors' example based upon the visual appeal of food.

\section{Media Psychology Behind Nutrition}

False promotions exacerbate the nutritional confusion of fluctuating government nutrition initiatives. The innocent viewer is thus adversely impacted by food marketing. The current generation of adolescents were subjected to multiple conflicting changes in nutrition ideals recommended by the U.S. government. Mark Bittman (2007), American food journalist, and former columnist for The New York Times, combines crucial information from various areas of research surrounding the evolution of nutrition. He explores the impacts of today's society and humanity's poor habits by interweaving ideologies and entreating a solution. "[W]e don't need animal products, and we certainly don't need white bread or Coke... both have been marketed heavily, creating unnatural demand... their production has been supported by government agencies at the expense of a more healthy and Earth-friendly diet" (Bittman, 2007, time 03:30).

In pop-culture television such as Gilmore Girls, these unhealthy calories are, independent of quantity, idealized as having no physical effect. This normalization and glorification of these foods perpetuates unhealthy dietary habits. Integrating Bittman's conclusions with various media psychology methodologies proves that society has been persuaded by pop-culture television to eat unhealthy foods. Idolized characters in television series, whether advertently or inadvertently, alter the habits of emotionally invested viewers who subsequently fall victim to the bandwagon effect. Dr. Bernard Luskin (1996) conducted a postgraduate study in psychology and media at the University of Southern California, et al., and published his findings in an article entitled Toward an Understanding of Media Psychology. As a Media Psychologist and child psychotherapist, he emphasizes that media psychology has become increasingly prevalent in today's society but is highly understudied. Luskin delves into the meaning of media psychology and analyzes the new theories and technologies that are arising from it. He also teaches about psychology awareness which "includes theories of intelligence, theories of learning, and media and learning. Understanding the elements of how and why people learn has revealed the effectiveness of media in learning" (Luskin, 1996, para. 16). There are many opportunities for understanding psychology in media and this could greatly impact a positive outcome for society as a whole. Analyzing this new concept of media psychology as a way to incorporate a healthy eating style will allow me to highlight the outcomes of my study and make conclusions to the possibility for a viewer to be impacted by the horrible eating habits in Gilmore Girls. Maybe the misinterpretations of unhealthy eating and healthy bodies in Gilmore Girls can be altered significantly by educating about media psychology and incorporating nutritional eating into the culture of television.

\section{Perceived Taste in Advertising}

The study of Harris and Bargh pinpoints the importance of "perceived taste" which is what advertisers hope anchors the viewers to their product and facilitates them to emulate alimentary behaviors through "subliminal seduction" (Harris \& Bargh, 2009; Key, 1973, as cited in Thomas, 2020, para. 2). This term was coined by Wilson Key, who "used his findings to prove the alleged power of subliminal advertising on human perception and inspired many television [sources]... to try the subliminal messaging technique on their programs" (Key, 1973, as cited in Thomas, 
2020, para. 2). It is imperative to consider, however, that not all placement of products is subliminal. Subliminal and straightforward product placement, methods that media professionals' practice through their quest to brand talent, are utilized in commercials and compelling pop-culture television. Branding publicists such as Shemarya (2020) promises "strategic partnerships, licensing, and business development" by "representing the world's top celebrities... in celebrity endorsements and brand building" (Shemarya, 2020). This practice has maximized "[a]n informational cascade [which] occurs when it is optimal for an individual, having observed the actions of those ahead of him, to follow the behavior of the preceding individual without regard to his own information." (Bikhchandani et al., 1992, para. 1). As exemplified by Shemarya and other businesses like it, a multibillion-dollar industry functions on the principals of informational cascade and the bandwagon effect in media.

\section{Brain Science of an Emotional Connection}

An emotional connection through perceived intimacy leads a viewer to connect to a compelling storyline and blindly follow celebrities' leads. Advertisers utilize cognitive science exemplified by Hirsch's studies, which "pinned down the specific neural regions that are responsible for helping us to keep track of the story line" (Hirsch, 2013 as cited in Plackett, 2019, para. 7). Her studies identify " 'a distributed cortical network' ... activated when the participant is shown a normal video sequence with a narrative flow" (Hirsch, 2013 as cited in Plackett, 2019, para. 7). According to Plackett's (2019) research, the collaborating system resides in the right hemisphere of the brain, the hemisphere that produces emotional responses. The field that links brain study and advertising is called neuromarketing. "[Investigating] how the human being perceives, processes, evaluates, reacts, and utilizes the external stimuli in the decision-making process in everyday activities and interactions" and exploring this newly emerging field of industrial neuroscience and its correlations to cognitive and emotional states of humans, helps professionals to understand "the relationship between customer behavior and the neurophysiological system" (Cherubino et al., 2019, para. 5). "In the 2000s, businesses and manufacturers did not want people to simply buy products; rather, they wanted to form relationships with consumers," and in this manner maintain clients by building an emotional connection (Batchelor, 2020b, para. 1).

\section{Para-social Relationships}

In The Cut, a subsidiary of New York Magazine geared to a predominantly feminine clientele, Romm (2016), Columbia University educated journalist, assures her readers that, as the title of her article states, "It's Okay to Think of the Gilmore Girls As Your Real Friends" (Romm, 2016, title). Horton and Wohl (1956) coined the term "para-social interaction" studying "mass media - radio, television, and the movies - ... [which gives] the illusion of face-to-face relationships with the performer" (Horton \& Wohl, 1956, para. 1). Romm (2016) references studies to explain the obscure edges between fiction and reality when we accept characters as trusted friends and guides through "parasocial interaction". They assert that the viewer is "subtly insinuated into the programme's actions and internal social relationships and, by dint of this kind of staging, is ambiguously transformed into a group which observes and participates in the show by turns" (Horton \& Wohl, 1956, para. 2). Human beings are influenced by the relationships we experience. Accordingly, "through communications campaigns, advertising, public relations, and marketing [media specialists] play a critical role in determining how people build their personal value systems" (Batchelor 2020b, para. 2). This practice has exponentially grown as evidenced by multinationals like Shemarya (2020) which implore spectators to have relationships with the celebrities in advertisements through branding campaigns. Similar tactics utilized over extended periods of time and in maxi-stories would certainly elicit a greater influence from the characters with which the spectators build their bonds (Batchelor 2020b). 


\section{Para-social Relationships Formed in Television}

How do the media professionals captivate even the most astute viewers in this manner? Horton and Wohl incorporate the "mode of direct address [of the actor who] talks as if he were conversing personally and privately" (Horton \& Wohl, 1956, para. 2). In I Love Lucy, for example, Lucille Ball, the "female lead" who "stretched the social norms" in her comedy and candor focused directly on the audience (Smuskiewicz, 2020, para. 9, para. 10). Media specialists' obscure edges between fiction and reality, the viewers then accept the characters as trusted friends and guides through this "para-social interaction" (Horton \& Wohl, 1956). Television, according to Horton and Wohl, is, in fact, a "public platform... extending the para-social relationship... to fictional characters... who appear in their capacities as real" (Horton \& Wohl, 1956, para. 6). Romm assures the Gilmore Girls' viewer, who feels like friends with the characters of Rory and Lorelai Gilmore, that "[1]ike any relationship, a parasocial relationship could take time to develop, and can take on varying levels of (perceived) intimacy" (Romm, 2016, para. 6). Thus, the viewer establishes a relationship of trust and follows her pseudo-friends' examples. Have not we all felt as though the characters in the shows we watched were friends or companions, and when the immersive experience ended, became saddened as we ended the figmented relationship? The media professionals through tone, words, and filming "[enhance] the presumed intimacy" utilizing all of these techniques in addition to "[enacting the role that] may be an idealized version of an everyday performance- [thus establishing] a 'successful' para-social... pattern" (Horton and Wohl, 1956, para. 7, para. 26). Gilmore Girls represents these practices, repetitively portraying eating practices which lightheartedly facilitate eaters to modify nutritional choices.

\section{Repercussions of Binging Television}

Our habits have greatly changed since the fifties, making our television watching continuous and thus increasingly more influential. Researchers such as Theodor Adorno exposed a potential impact of television to alter viewers' habits warning of " "the guise of fake realism... [and the] nefarious effect"” of viewing television (Adorno, 1954 as cited in Pitre, 2019, para. 2). We know that "with the modern binge model of consumption... [t]he concept of television flow [has greatly expanded]" (Pitre, 2019, para. 5). In Why We're Wired to Binge-Watch TV, Jordan Lewis (2014), $\mathrm{PhD}$, warns of "[a] new report [that] shows that the average American watches more than five hours of television daily" and "that 76 percent reported binging as a welcome refuge from their busy lives" (Lewis, 2014, para. 14, para. 13). As Pitre (2019) discussed, there are algorithms in place to study and understand a viewer's preferences, but also to take advantage of viewers' tendencies when making recommendations. This implores viewers to keep watching while increasing emotional investment, susceptibility to para-social relationships, and blind trust. Netflix Media Center reports that Gilmore Girls: A Year in the Life, a follow-up series, holds the number one spot for the "Top 20 Binge Raced Shows" (Netflix Media Center, 2017, para. 10). Shows such as Gilmore Girls come into our home and through personality, filming, staging, and dialogue of common human experience, render themselves unexpected influencers.

\section{Emotional Investment Fostered Binging}

Binge watching provides more concentrated time for influencing habits. We watch characters intently, and inadvertently jump on the bandwagon when we experience tantamount emotions. Viewers learn by example to eat in order to kwell any natural fluctuations in human emotions. Dr. Diodoro (2015), specializing in psychiatry and scientific evidence-based medicine journalism, examines the intrigue of movies through media psychology. When a viewer becomes emotionally invested, gaps in cognitive decision making tend to result (Diodoro, 2015). This is evident in Gilmore Girls when Lorelai and Rory guzzle caffeine, icecream, and fast food treats at the onset of any natural ebb and flow of life's imbalanced events which provoke human emotion. Diodoro clarifies that media psychology 
speaks to this vulnerability in emotions. In the quest to relate the affective immersion of adolescent audiences engaging in pop-culture television series, Diodoro's studies of the affective realm could be applied to alter eating habits. Given this subliminal identification with the television characters, messages they transmit could alter attitudes toward diet. The innocent viewer adopts the behavior portrayed by her television shows; when emotions hit, junk food satiates.

\section{Methodology}

\section{Participants}

The subjects of the experiment were female adolescents and early adults previously engaged in pop-culture television. Early adults are included because they are still partially in emotional adolescence (Guyer, 2016). I was able to therefore broaden the demographics of participants while maintaining credibility. With this addition to the participant pool, I was able to conduct a snowball sampling in the short period of time allotted by the parameters of The AP Capstone Research Course and the approval times of my high school's review board. The snowball sampling method was utilized because it draws upon the existing participants to bring upon new participants of the same gender and age category.

\section{Materials}

I conducted the study with three consecutive surveys administered throughout carefully designated milestones within the study. These surveys asked questions that incorporated my topics of bandwagon effect and nutrition in a manner that would appeal to the demographic of the participants and ensure that each would spend the required time to complete all three parts. The survey was designed to ascertain demographics and habits, and then transition into a witty and inviting tone. This methodology facilitated the participants to feel confident in answering honestly. A few seemingly random questions were interwoven into the survey in order to conceal the topic and avoid biased responses.

\section{Design}

The three surveys administered composed a correlational study: one that preceded the viewing of Gilmore Girls, one that immediately followed the viewing of Gilmore Girls, and one that was administered a week later. The study could also be considered to have a mixed-methods approach because qualitative data was gathered, and a quantitative analysis of the qualities exhibited was performed. The design gauged the presence of a change in nutritional habits after viewing Gilmore Girls while seeking the influence of bandwagon effect. Questions were designed to allow for easy data manipulation and exploration in order to search for associations between variables in the data. They were also formulated in a way that allowed for statistical analysis (or that allowed for simple conversion from qualitative to quantitative data) so that an A/B test could be performed, and statistical significance of any noted association could be found.

\section{Procedure}

The output from the participants was submitted through an online survey conducted through Google Forms and further communication occurred through email. The procedure took place remotely in the participants' homes. The data was recorded by transferring responses from the survey into a Microsoft Excel Spreadsheet and from there to a Jupy- 
ter Notebook (a platform that enables coding in Python and therefore fluid data analysis). The non-responses were noted and removed.

Steps to the study:

1. All participants received a document informing them how to properly perform the study and directing to read and sign the required consent form delineating the study.

2. Participants were directed to have certain healthy and unhealthy foods and drinks within grasp during viewing. Healthy options included fruit and/or vegetable crudité as well as water. Unhealthy options included buttered popcorn, wrapped candy, and coffee. Note that participants ate and drank of their own volition.

3. Participants filled out a brief survey part I (five - seven minutes) (Appendix A).

4. They watched two - three episodes of Gilmore Girls on Netflix (assuming participants had access to this show).

5. After viewing episodes of Gilmore Girls, participants filled out survey part II (three minutes) (Appendix B). This part included food-related questions.

6. A week later, participants received survey part III (7-10 minutes) (Appendix C) asking them to evaluate eating habits.

7. Once collected, the data was examined and transferred to the aforementioned platform.

8. After making initial observations, I further analyzed the data by searching for associations and analyzing the correlation coefficients between questions. I then performed A/B tests, both on the overall data and on specific subsets of the data, using several questions that allowed me to compare the distributions of the number of unhealthy foods chosen both before and after watching Gilmore Girls. My test statistic was the difference of means between both groups.

\section{Results and Limitations}

My hypothesis was partially proven and warrants further study. The responses to one determining question were inconclusive due to faulty wording. The short-term effects were validated in the baseline and second surveys but the analysis of the third survey rejected the hypothesis due to statistical insignificance. Although my hypothesis was compromised, some results prove beneficial.

As the Gender of the Main Dietary Decision Maker graph depicts, female protagonists lead nutritional household choices. The Dietary Decision Makers' Main Dietary Influence for Household graph suggests that media is less influential than childhood family traditions. Correspondingly, conducting further studies on the specific impact of media could further advance my hypothesis due to the fact that media has been proven to have an impact. 


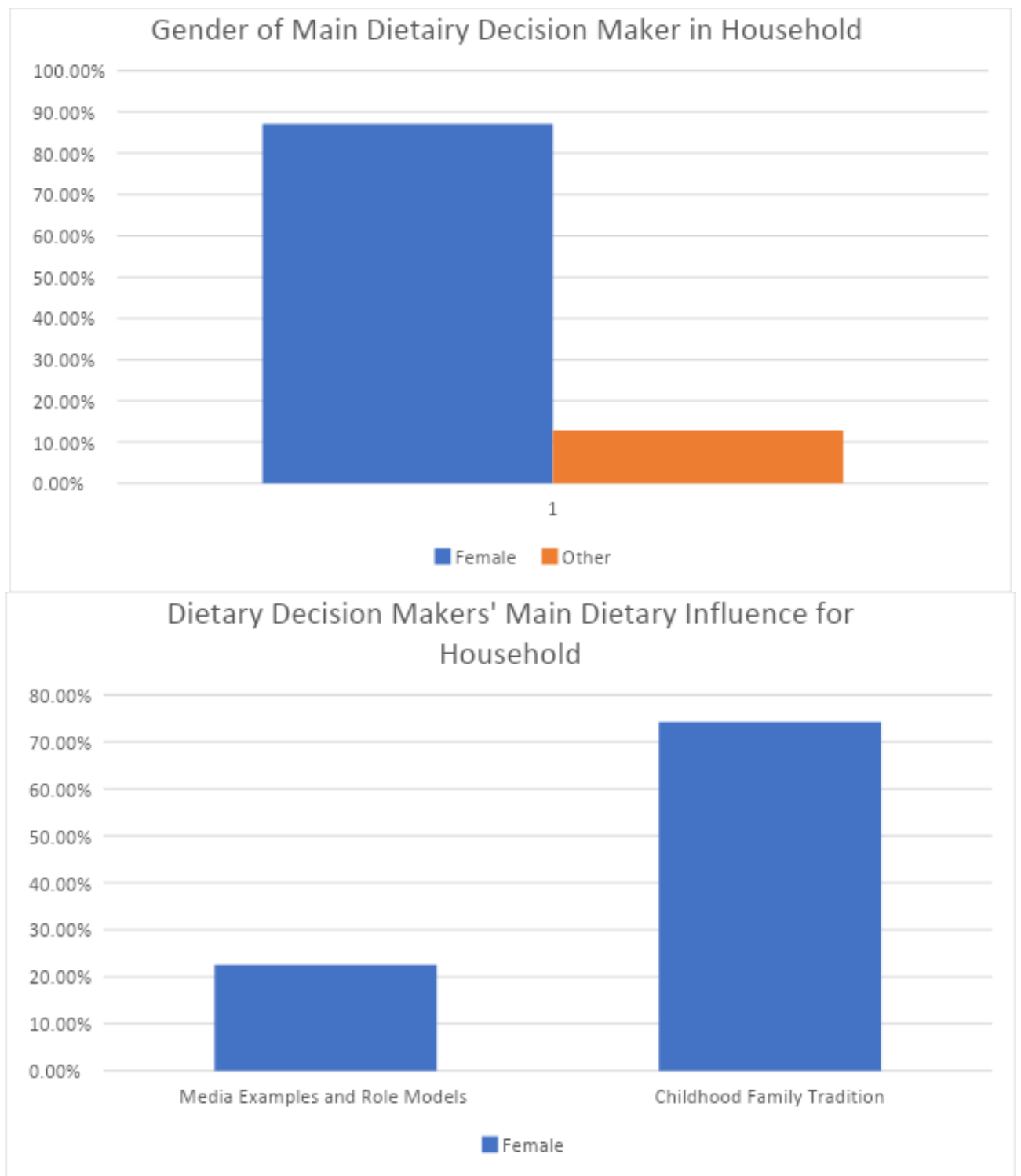

The show had the effect of altering nutritional lifestyle; as evidenced by the Desired Foods Before and After Gil-

\section{Desired Foods Before and After Gilmore Girls}

\section{$80.00 \%$}

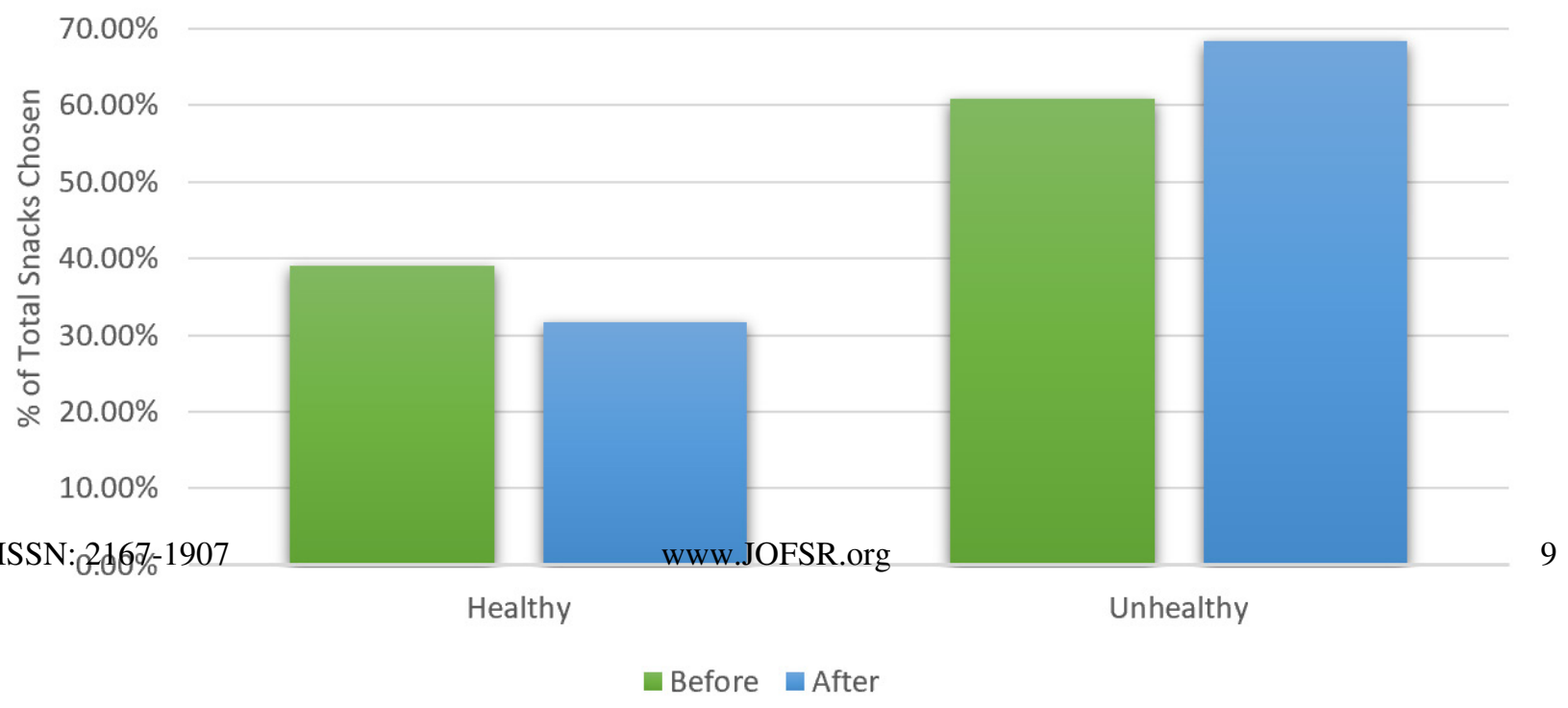


more Girls graph, calculations resulted in a ratio of 110:51, selecting unhealthy to healthy snacks. This trend continued a week after watching. The third graph charts results of the following process: After downloading the data from the survey into a CSV format, I opened a Jupyter Notebook to begin my analysis in Python programming language, imported the data, and created healthy and unhealthy variables for the survey preceding viewing and the one a week

after. Using these data points, independently for each survey, I calculated the healthy and unhealthy percentages. Following these calculations, I collected the data into a bar graph for easier analysis. According to this graph below, the number of healthy foods chosen significantly decreased after watching Gilmore Girls (39.1026\% to 31.6770\%), while the number of unhealthy foods chosen significantly increased after watching Gilmore Girls $(60.8974 \%$ to $68.3230 \%$ ). This supports my hypothesis that observing the protagonists' consumption of unhealthy foods in popculture television creates an emotionally invested viewer influenced by bandwagon effect $(94.6000 \%$ noted that they were emotionally invested). In comparing the data from the surveys, it is evident that watching Gilmore Girls had an effect on the diet of female adolescent/early adulthood viewers.

During the analysis of the data, an A/B test was run to determine whether the hypothesized difference in unhealthy foods chosen by females before and after watching Gilmore Girls was statistically significant. The null hypothesis was that the distribution of unhealthy foods chosen was the same for adolescent females both before and after watching Gilmore Girls. The alternative hypothesis was that the distribution of unhealthy foods chosen was different (unhealthier after) for adolescent females both before and after watching Gilmore Girls. The test statistic was the difference in means between before and after watching the show. The observed difference in means from the data was approximately 0.6486 . Then the labels of the original samples were shuffled in order to find a simulated test statistic, and this process was repeated 50,000 times. For visualization purposes, I created a histogram of the simulated values of the test statistic, and then calculated the empirical P-value by counting how many times the simulated test statistic was greater than or equal to the observed test statistic, dividing that by 50,000, the total number of repetitions of the simulations done. When this process was completed, I found the P-value to be 0.1290. Since the Pvalue of 0.1290 is greater than the standard alpha level of 0.05 , we do not have statistically significant evidence to reject the null hypothesis in favor of the alternative hypothesis. I do not have good evidence that the true mean of unhealthy foods eaten after watching Gilmore Girls was greater than the true mean of unhealthy foods eaten before Gilmore Girls. This is contrary to the overall trends in the data, including other questions, which could be due to several possible confounding factors. This includes that not all of the necessary conditions were met; this was not an overseen randomized sampling. Therefore, this sampling error means that the sample utilized in this experiment did not properly represent the population of female adolescents.

The above information shows a possible error in question design. There were, however, other questions that showed results favorable to the alternative hypothesis. When asked how the participants' eating habits changed as a result of watching Gilmore Girls, $72.9730 \%$ of the participants indicated that their eating habits had consequently become unhealthier. A randomized controlled follow-up experiment in person instead of online would therefore serve to clarify the results and prove or disprove the hypothesis. The follow-up will be formulated with easier to identify and more objective metrics such as a basket of foods classified as unhealthy and healthy and objectively measuring what foods the participants chose. In order to improve the validity of my study and have statistically significant results, it would need to be repeated over a series of years, as well as over various time frames of watching the show and with other pop-culture television shows. This would require time not available through the parameters of the AP Capstone Research Class.

The aforementioned lack of a random sample presenting an issue of undercoverage created results unrepresentative of a diverse sample from various backgrounds and demographics. In addition to previously stated confounding factors, there are a few more to take into consideration. In future studies, gender fluidity should be a consideration, possibly running inquiries with nonbinary participants. The manner in which the study was enacted online diminished participant accountability. In addition, I would need to be able to test how many episodes viewed warrant emotional investment of viewers. Finally, it is imperative to note the ramifications of the administrative 
learning curve of this pilot year of the AP Capstone Research in my school, which I believe to have diminished the quality of my study. Due to the new emergence of this program in my high school, the review board took months to approve plans of the studies, minimizing the time-frame in which my study could be administered before the due dates.

\section{Conclusion}

Since the nutritional habits of the female adolescent viewers of pop-culture television were impacted by the bandwagon effect (albeit statistical insignificance in my study), then informed society has an avenue to initiate a venture through pop-culture television in order to repair the poor culture of eating developed over the past several decades. The larger scope of my study would expand the possibilities of a popular pop-culture television series to alter the nutritional habits of female adolescents by incorporating cognitive bias such as the bandwagon effect in relation to nutritional suggestions into the scripts of these programs. Reverse engineering the results of this microcosmic study within this realm could potentially reinvigorate nutritional conventions among female adolescent viewers and subsequently ameliorate future nutritional practices. The results of this study suggest that my hypothesis might be proven if confounding factors were illuminated, and thus warrants subsequent research.

Acknowledgements:

Thank you, Mrs. Cunningham, for all of your guidance and support! Your expertise in steering me during my writing process was invaluable.

\section{References}

Andersen, K., \& Kuhn, K. (Directors). (2017). What the Health [Video file]. United States: A.U.M. Films \& Media. Retrieved May 16, 2020, from https://www.netflix.com/watch/80174177?trackId=13752289

Avila, R. (2020). Housewives in the 1950s: Stereotypes and Reality. In Pop Culture Universe: Icons, Idols, Ideas. Retrieved from http://popculture-abc-clio-xana.orc.scoolaid.net/Search/Display/2149366

Batchelor, B. (2020). Advertising in the 1950s. In Pop Culture Universe: Icons, Idols, Ideas. Retrieved from http://popculture-abc-clio-xana.orc.scoolaid.net/Search/Display/1895709

Batchelor, B. (2020). Advertising in the 2000s. In Pop Culture Universe: Icons, Idols, Ideas. Retrieved from http://popculture-abc-clio-xana.orc.scoolaid.net/Search/Display/1516357

Bikhchandani, S., Hirshleifer, D., \& Welch, I. (1992). A Theory of Fads, Fashion, Custom, and Cultural Change as Informational Cascades. Journal of Political Economy, 100(5), 992-1026. doi:10.1086/261849

Bittman, M. (2007, December). Transcript of "What's wrong with what we eat". Retrieved from http://www.ted.com/talks/mark bittman on what s wrong with what we eat/transcript?language=en.

Chappelow, J. (2020, February 05). Bandwagon Effect Definition. Retrieved May 16, 2020, from https://www.investopedia.com/terms/b/bandwagon-effect.asp

Cherubino, P., Martinez-Levy, A. C., Caratu, M., Cartocci, G., Di Flumeri, G., Modica, E., ...Trettel, A. (2019). Consumer Behaviour through the Eyes of Neurophysiological Measures: State-of-the-Art and Future Trends. Com- 
putational Intelligence and Neuroscience, NA. Retrieved from https://link.gale.com/apps/doc/A606670763/PPPC?u=nys1 li calhn\&sid=PPPC\&xid=c0af6ae2

Diodoro, D. (2015, December 15). Ecco Perché Andiamo al Cinema (Per Piangere o Spaventarci). Retrieved from https://www.corriere.it/salute/neuroscienze/15 dicembre 11/perche-andiamo-cinema-piangere-o-aver-paura0850ebba-a010-11e5-9e42-3aa7b5e47d96.shtml.

DSEP, B. (2019, September 30). Data Science. Retrieved from https://www.inferentialthinking.com/chapters/01/what-is-data-science.html

Gaines Lewis, J. (2014, March 11). Why We're Wired to Binge-Watch TV. Retrieved from https://www.psychologytoday.com/us/blog/brain-babble/201403/why-were-wired-binge-watch-tv.

Gurau, C. (2015). The Effect of Marketing Promotions on Customers' Cognitive Biases. The Proceedings of the International Conference, Marketing - from Information to Decision, (8), 48+. Retrieved from https://link.gale.com/apps/doc/A438290608/AONE?u=nysl li bocesnas\&sid=AONE\&xid=2dc9eb4c

Guyer, A., Silk, J., \& Nelson, E. (2016, November). The Neurobiology of the Emotional Adolescent: From the Inside Out. Retrieved May 16, 2020, from https://www.ncbi.nlm.nih.gov/pmc/articles/PMC5074886/

Harris, J. L., \& Bargh, J. A. (2009). Television Viewing and Unhealthy Diet: Implications for Children and Media Interventions. Health communication, 24(7), 660-673. https://doi.org/10.1080/10410230903242267

Horton, D., \& Wohl, R. (1956). Extract from 'Mass Communication and Para-social Interaction: Observations on Intimacy at a Distance'. Retrieved from http://visualmemory.co.uk/daniel/Documents/short/horton and wohl 1956.html?LMCL=N6S3ER.

Jones, M. O. (2007). Food choice, Symbolism, and Identity: Bread-and-Butter Issues for Folkloristics and Nutrition Studies (American Folklore Society Presidential Address, October 2005). Journal of American Folklore, 120(476), 129+. Retrieved from https://link.gale.com/apps/doc/A159646071/AONE?u=nysl li halfhol\&sid=AONE\&xid=e8b65560

Kealey, T. (2018, July 09). Why Does the Federal Government Issue Damaging Dietary Guidelines? Lessons from Thomas Jefferson to Today. Retrieved May 16, 2020, from https://www.cato.org/publications/policy-analysis/whydoes-federal-government-issue-damaging-dietary-guidelines-lessons

Lan, Y., Mohr, C., Hu, X., \& Kuhn, G. (2018). Fake science: The Impact of Pseudo-Psychological Demonstrations on People's Beliefs in Psychological Principles. PLoS ONE, 13(11), e0207629. Retrieved from https://link.gale.com/apps/doc/A563518605/PPPC?u=nysl li halfhol\&sid=PPPC\&xid=f298c21f

Luskin, B. J. (1996, February). Toward an Understanding of Media Psychology. T H E Journal [Technological Horizons In Education], 23(7), 82+. Retrieved from https://link.gale.com/apps/doc/A18032641/AONE?u=nysl li halfhol\&sid=AONE\&xid=e763c53c

Maghbouleh, N. (2020). Television Shows and American Culture. In Pop Culture Universe: Icons, Idols, Ideas. Retrieved from http://popculture-abc-clio-xana.orc.scoolaid.net/Search/Display/1364001 
Media psychology; investigators at the University of Delaware publish new data on media psychology. (2008, May 12). Psychology \& Psychiatry Journal Retrieved from https://search.proquest.com/docview/214842109? accountid=37387

Modica, E., Rossi, D., Cartocci, G. and Martinez Levy, A. (2019). Neurophysiological Responses to Different Product Experiences. [online] Available at:

https://www.researchgate.menet/publication/327852450 Neurophysiological Responses to Different Product Exp eriences

Ninaunited4sc. (2020, April 28). Bandwagon Effect: Hop On! Retrieved May 16, 2020, from

https://academy4sc.org/topic/bandwagon-effect-hop-on/?utm campaign=

Oliver, J. (2010, February). Teach Every Child About Food. Retrieved from http://www.ted.com/talks/jamie oliver\#t-944116.

Pitre, J. (2019). A Critical Theory of Binge Watching | JSTOR Daily. [online] JSTOR Daily. Available at: https://daily.jstor.org/critical-theory-binge-watching/.

Plackett, B. (2019). Watching TV Makes Your Brain Cells Go Nuts. [online] Business Insider. Available at: https://www.businessinsider.com/how-your-brain-reacts-to-watching-tv-2013-5

Ready, Set, Binge: More Than 8 Million Viewers 'Binge Race' Their Favorite Series. (n.d.). Retrieved from https://media.netflix.com/en/press-releases/ready-set-binge-more-than-8-million-viewers-binge-race-their-favorite$\underline{\text { series }}$

Researchers at University of Louisville Report Findings in Brain and Behavior (Cortical morphometry and structural connectivity relate to executive function and estradiol level in healthy adolescents). (2019, October 19). Obesity, Fitness \& Wellness Week, 5082. Retrieved from https://link.gale.com/apps/doc/A602550552/HRCA?u=nysl li bocesnas\&sid=HRCA\&xid=9e680f51.

Romm, C. (2016, April 19). It's Okay to Think of the Gilmore Girls As Your Real Friends. Retrieved from https://www.thecut.com/2016/04/it-s-okay-to-think-of-the-gilmore-girls-as-your-real-friends.html

Shemarya. (n.d.). Retrieved from

https://www.shemarya.com/

Sherman-Palladino, A. (2017, October 1). Retrieved May 25, 2020, from

https://www.netflix.com/watch/80014135?trackId $=13752289 \& \mathrm{tctx}=0,0$, aa4c215e0f1489c8f247073869d61f43e8d97 ade:4dd4f6ab8899524a220a39d48cefa276b4064283

Smuskiewicz, A. J. (2020). I Love Lucy (TV, 1951-1957). In Pop Culture Universe: Icons, Idols, Ideas. Retrieved from http://popculture-abc-clio-xana.orc.scoolaid.net/Search/Display/1497691

Thomas, L. (2020). Subliminal Messages. In Pop Culture Universe: Icons, Idols, Ideas. Retrieved from http://popculture-abc-clio-xana.orc.scoolaid.net/Search/Display/1507525 